$\mathbb{P}$ periodica polytechnica

Civil Engineering

$54 / 2$ (2010) 163170

doi: 10.3311/pp.ci.2010-2.12

web: http://www.pp.bme.hu/ci

(c) Periodica Polytechnica 2010

RESEARCH ARTICLE

\section{Equivalent thermal conductivity of steel girders with slotted web}

Julianna Lipták-Váradi

Received 2010-04-27, revised 2010-06-24, accepted 2010-11-26

\begin{abstract}
Lightweight building methods are spreading all over the world from the Scandinavian countries and North America and can also be seen more often in Hungary. One of the areas of this building method is a façade containing thin-walled slotted steel girders, called as thermal studs, also. Due to the slots in the web there is an increased heat path length inside the steel elements, so the heat bridges caused by the framing will be less, compared to the case of a standard geometry of the solid ones. Research has been carried out in the past decades in the development of this wall system. One approach was to investigate the building physics properties (thermal and vapour transmittance, fire protection, acoustics). This paper presents the calculation method of the equivalent thermal conductivity of the slotted webs of the steel girders. Simulations were carried out with the computational programmes ANSYS 11.0 and HEAT3 5.0. To check the validity of the thermal conductivities, wall sections containing slotted steel girders were simulated by using either the original slotted elements and after it the equivalent section. The comparison of the models shows good agreement between the original slotted girder and the equivalent solid sections. Special perforation geometries were also developed to achieve a better thermal performance.
\end{abstract}

\section{Keywords}

lightweight $\cdot$ slotted web $\cdot$ thermal stud $\cdot$ steel $\cdot$ equivalent thermal conductivity

\section{Acknowledgement}

This work is connected to the scientific program of the "Development of quality-oriented and harmonized $R+D+I$ strategy and functional model at BME” project. This project is supported by the New Hungary Development Plan (Project ID: TÁMOP4.2.1/B-09/1/KMR-2010-0002).

\section{Julianna Lipták-Váradi}

Department of Architectural Engineering, BME, H-1111 Múegyetem rkp. 3-9., Budapest, Hungary

e-mail: varadij622@gmail.com

\section{Introduction}

Lightweight building systems and methods are developing and spreading rapidly all over the world. In a lightweight building system, load bearing elements and partitions are separate units and this is an important precondition of multipurpose use. The partitions are multilayer types, with using different materials each selected for its characteristic properties [1].

One of the several types of the different lightweight building methods is the façade system containing slotted steel girders. The façades can be applied in two different ways: as a load bearing exterior wall of a new additional floor of existing buildings, as infill or as a curtain wall for reconstruction or newly built reinforced concrete skeleton buildings [4].

A façade solution can be seen in Fig. 1. The materials and layers of the façade are $\mathrm{C}$ and $\mathrm{U}$ shaped slotted steel girders as load bearing framework, infill insulation vapour barrier layer, gypsum boards and additional layers, such as exterior insulation with plastered cladding. Other additional claddings can be used also, e.g. brick with ventilated air gap or metal claddings.

According to Höglund and Burstrand the advantage of this system is that due to the slotted web there in an increased heat path length inside the steel elements, so the heat bridges caused by the framing will be less, compared to the solid ones [3].

\section{Literature study}

The lightweight buildings, building constructions of today developed in a long historical process. During this, many types of lightweight buildings and methods developed on the different continents and regions [5]. In the prehistoric ages first pile dwellings were built, later buildings with wooden framework containing infill natural materials can be seen, e.g. in the Hungarian rustic architecture, or in the German areas the so called Fachwerk, from the beginning of the sixth century. At the beginning of the twentieth century the glued laminated timber and industrialization (prefabricated elements and panels) appeared. Around the 1940s steel appeared to substitute wood in the buildings in the United States of America. First it was used as interior walls, then as a result of development also load bearing elements were made. It was first used for single family houses in the 


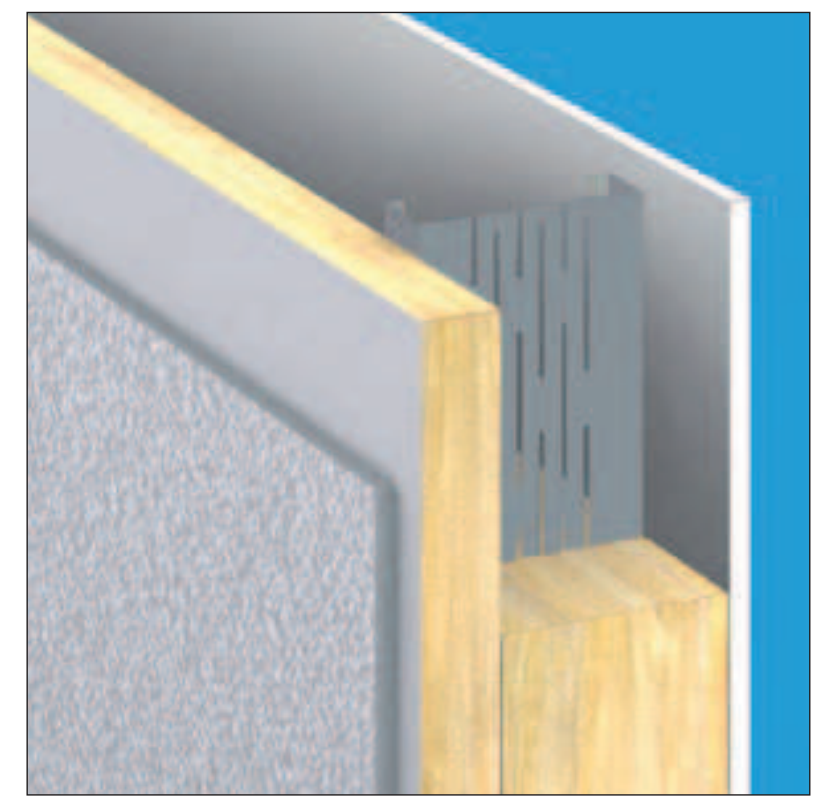

Fig. 1. Cross section of the façade system with plastered exterior cladding [2]

1960s.

The advantage of steel-framed houses over wooden houses such as greater durability, better recyclability and prevention of deforestation make them desirable as a new, environmentfriendly building construction method [6]. Nowadays there is partial or total prefabrication in the factories. One of these systems is lightweight façade system containing steel girders.

The researches about lightweight facades containing steel studs can be found in two separate ways: one is the behaviour of the steel stud from a stability point of view, because an important tendency of the civil engineering industry during the last few decades is the application of more slender elements and structures. This trend is reflected e.g., by the wider and wider application of these cold-formed steel members, supported by developments in the production technology as well as improvements in design methods, design standards and computational techniques [7]. Besides stability researches, the other is building physics behaviour (heat and vapour conduction, acoustics, fire resistance) of the constructions containing these elements are also important. One of the main driving forces in the development is to increase thermal efficiency of the façade system. The thermal resistance of the facade is based on the individual contributions of each component within the assembly. This can be determined in three ways: hand calculation, computer modelling and physical testing, such as thermovision or hot box testing [11]. The challenge of further reducing the heat flow through steel framing members led to some innovative, thermally efficient steel studs in the United States of America. Several types of thermal breaking systems were developed and tested during the last decade, e.g. in the laboratory of Jan Kosny: insulating sheathing; several types of distance washers (spacers) to reduce contact area between the steel studs and exterior sheathing; re- flective surfaces were added to spacer systems to improve Rvalue of air space; studs with reduced stud depth area or two rows of studs; several unconventional shapes of studs; local foam insulation for studs, and a concept of combined foam/steel studs [8]. To provide a comparable thermal performance to that of wood frame walls, expanded channels, open-webs and light channels were fabricated, also.

In the early 1980's Dofasco patented the thermal stud which utilized perforations in the web of the stud to increase heat path length. This design modification resulted in a $45 \%$ improvement in thermal resistance [11].

Calculation methods were also developed, e.g. ASHRAE (American Society of Heating, Refrigerating and AirConditioning) zone method. This method has been improved throughout the years in order to increase its accuracy reaching levels around $2 \%$. But the number of variations is limited. The thermal efficiency is calculated experimentally by using the HotBox method [9]. In the last decades the speed of development due to the computer techniques is increasing.

Amundarain et al suggested that one of the most efficient techniques to reduce the thermal bridge is the modification of the steel stud by the production of straight slots [10]. In our research area the thermal resistance of this type of façade is being under research. The basic idea of the research is to achieve an efficient façade construction with favourable thermal properties. One solution is the use and development of slotted steel studs or as it is called thermal studs [12]. Blomberg has shown that the material thickness of the slotted steel stud would have to be reduced by a factor of six to achieve the equivalent thermal properties in a standard profile [13]. Salonvaara and Nieminen made hygrothermal simulations and laboratory testing and showed, that the thermal properties of a thermoprofile are comparable to wooden load-bearing frame structures used in lowenergy buildings, which makes it possible to use steel members in energy-efficient walls as well [14].

\section{The thermal properties of the slotted steel girders}

In this chapter the slotted web of the steel $\mathrm{C}$ and $\mathrm{U}$ shaped girders will be examined. In this case the variations of the basic perforation geometry (straight slots) can be seen. The first question is how does the change in the perforation geometry effect the rate of the heat flow through the steel web. The second question is if the slotted part of the web could be taken into account in heat transfer calculations by using these equivalent thermal conductivities.

As a different approach, equivalent thicknesses were also calculated. However, the difference between the equivalent thicknesses connected to the slot geometries differed so less from each other, that they cannot be used in calculations when the question is the effect of the different slot geometries. 


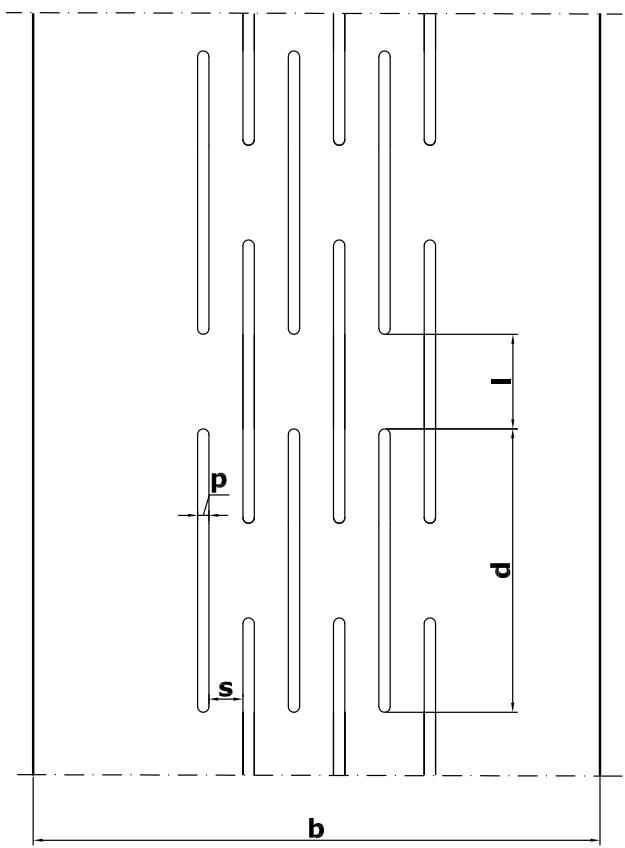

Fig. 2. The basic parameters of the slotted web

\subsection{The model}

The basic web plate parameters, which will be varied in the following calculations, can be seen in Fig. 2 and Table 1 . The simulations were carried out by varying one parameter at one time and keeping others constant at the basic values [15]. The web plate thickness was taken to $1 \mathrm{~mm}$ in every simulation.

\subsection{The finite element model}

The simulations of the heat conduction behaviour of the slotted web were carried out with the finite element programme ANSYS (version 11.0). The heat conductional property of the steel was taken to $\lambda=60.4 \mathrm{~W} / \mathrm{mK}$. The film coefficients were $h_{i}=8 \mathrm{~W} / \mathrm{m}^{2} \mathrm{~K}$ and $h_{e}=24 \mathrm{~W} / \mathrm{m}^{2} \mathrm{~K}$. The calculations were made with $1 \mathrm{~K}$ temperature difference on the two flange sides of the slotted webs. The size of the models and the necessary finite element numbers were calibrated in the first step. As the results of the calibration the sizes of the finite elements were taken to $0.5 \mathrm{~mm}$, the length of the steel element in the model was put to $200 \mathrm{~mm}$ (see Fig. 3).

The cavities formed by the slots will probably be filled with air instead of insulation. The equivalent thermal conductivity for the air gap is $\lambda_{\text {eq,airgap }}=0.026 \mathrm{~W} / \mathrm{mK}$, if the width of the slot is $p=3 \mathrm{~mm}$, according to Blomberg. The heat transferred by radiation and convection inside the gaps is about the same as that transferred by pure conduction in the insulation. Thus, the heat flow between the gaps is negligible compared to the flow along the steel [13]. To proof this statement, the differences between the different models can be seen in Table 2 . There are four calculations found in Table 2. The first result occurs when the slots are empty and not filled with material. In the second, third and fourth steps there is: 1. insulation material with extremely low thermal conductivity value, 2 . slots filled with air, 3. slots filled with usually used insulations material.

The conclusion is that the secondary impact in the slots can be neglected because of the small difference occurred in the results, so in the simulations the material "air gap" can be used. Heat transfer in the web can be assumed to be pure heat conduction [14].

\subsection{The equivalent thermal conductivities}

The equivalent thermal of the slotted webs can be calculated according to the following equation:

$$
\lambda_{\text {eq }}=\lambda_{\text {perf }}=\frac{d}{\frac{1}{U}-\frac{1}{h_{e}}-\frac{1}{h_{i}}}
$$

where

- $\lambda_{\text {perf }}$ is the thermal conductivity of the slotted web calculated from the computational simulation results $[\mathrm{W} / \mathrm{mK}]$

- $h_{i}$ is the internal surface heat transfer coefficient $\left[\mathrm{W} / \mathrm{m}^{2} \mathrm{~K}\right]$

- $h_{e}$ is the external surface heat transfer coefficient $\left[\mathrm{W} / \mathrm{m}^{2} \mathrm{~K}\right]$

- $d$ is the width of the slotted web [m]

- $U$ is the thermal transmittance value $\left[\mathrm{W} / \mathrm{m}^{2} \mathrm{~K}\right]$.

The thermal transmittance value found in the equation comes from the computational simulations. The internal and external surface heat transfer coefficients are fixed values according to the Hungarian building physics standards and regulations. The values of them can be found in the beginning of Section ??.

In Fig. 4 the effect of changing the single slot width can be seen for two different web heights, 100 and $200 \mathrm{~mm}$. As the slot width increases, the equivalent thermal conductivity decreases. This decrease is more efficient in the case of using $200 \mathrm{~mm}$ web height. At $9 \mathrm{~mm}$ slot width there is a negligible difference between the equivalent thermal conductivity values of the webs with different heights.

In Fig. 5 the effect of changing the single slot length and the effect of the number of rows of slots can be seen. The increase in the number of rows of slots and the increase of the single slot length decrease the thermal conductivity.

The effect of changing the solid length between the slots in vertical direction can be seen in Fig. 6 As the solid length increases the thermal conductivity increases, also.

Fig. 7 shows the effect of changing the solid length between the slots in vertical directions. As the solid length increases, the value of the equivalent thermal conductivity increases, also.

Based on Figs. 6 and 7 it can be said that from a thermal behaviour point of view it is preferable to keep the slots as close to each other as possible in both vertical and horizontal direction.

The effect of changing the web height and using the same perforation geometry can be seen in Fig. 8. As the web height increases, the equivalent thermal conductivity value increases, also. 
Tab. 1. The geometric parameters of the slotted web

\begin{tabular}{cccc}
\hline web plate parameters & parameter ranges [mm] & basic value [mm] \\
\hline web plate width & $b$ & $100-300$ & 100 \\
number of slot lines within the slotted region & $n$ & $2-6$ & 6 \\
width of single slot & $l$ & $10-60$ & $1-9$ \\
length of a single slot & $p$ & $65-85$ & 75 \\
solid length between every two adjacent slots (vertical direction) & $s$ & $1-12$ & 8 \\
\hline
\end{tabular}
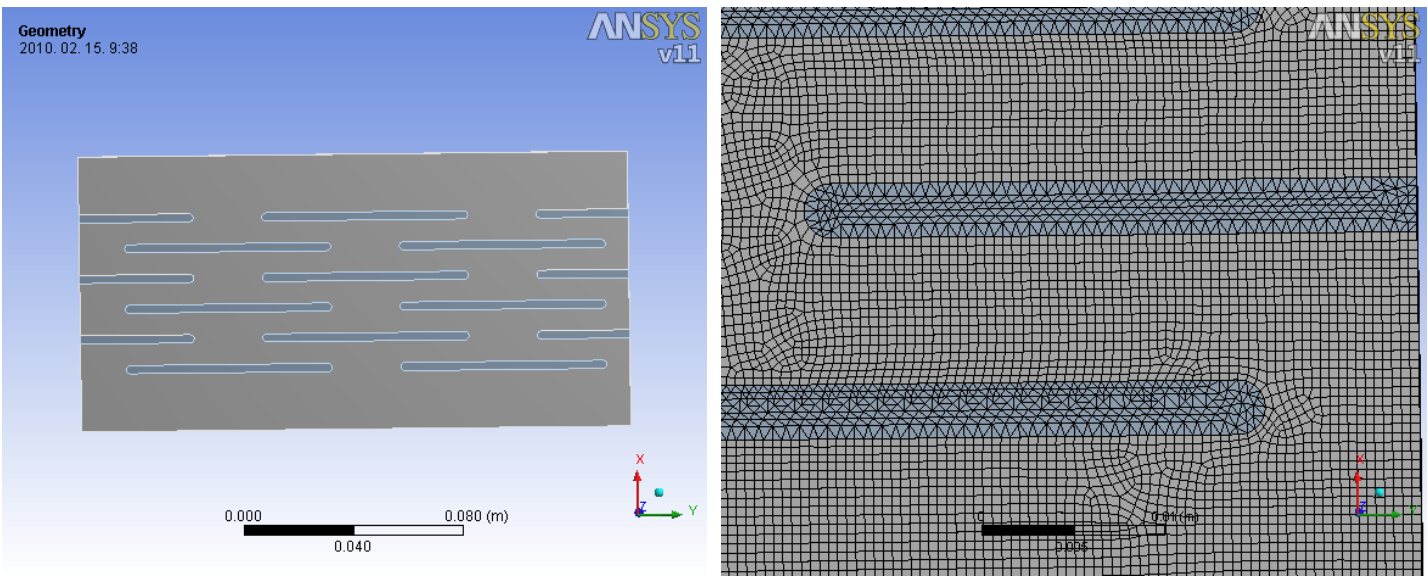

Fig. 3. The model of the slotted web and a part of the finite element mesh around the slots

Tab. 2. The thermal conductivity simulation for the slots of the steel web

\begin{tabular}{ccccc}
\hline $\begin{array}{c}\text { material in } \\
\text { the perforations }\end{array}$ & $\lambda_{\text {perforation }[\mathrm{W} / \mathrm{mK}]}$ & $\lambda_{\text {steel }}[\mathrm{W} / \mathrm{mK}]$ & $q\left[\mathrm{~W} / \mathrm{m}^{2}\right]$ & $\begin{array}{c}\text { difference in heat flow compared } \\
\text { to the model containing air gap }\end{array}$ \\
\hline $\begin{array}{c}\text { empty } \\
\text { extra insulation }\end{array}$ & 0.0005 & 60.4 & 5.2825 & $0.45 \%$ \\
air gap & 0.026 & 60.4 & 5.2830 & $0.44 \%$ \\
insulation material & 0.035 & 60.4 & 5.3064 & - \\
\hline
\end{tabular}

equivalent $\lambda(\mathrm{W} / \mathrm{mK})$

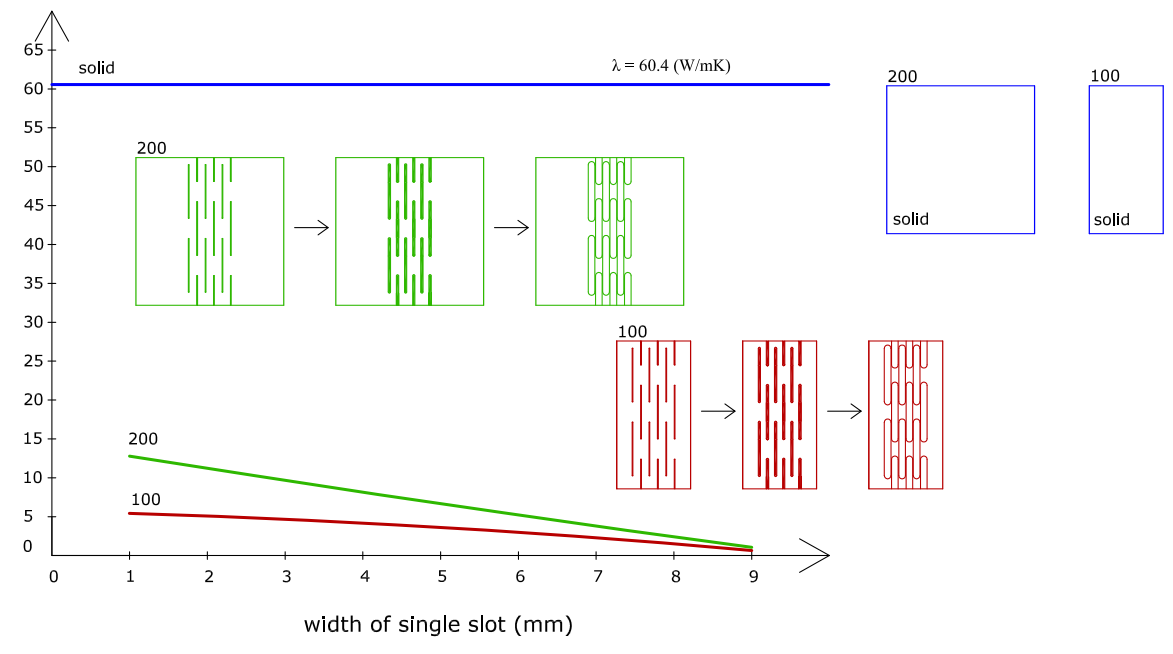

Fig. 4. The effect of changing the single slot width 


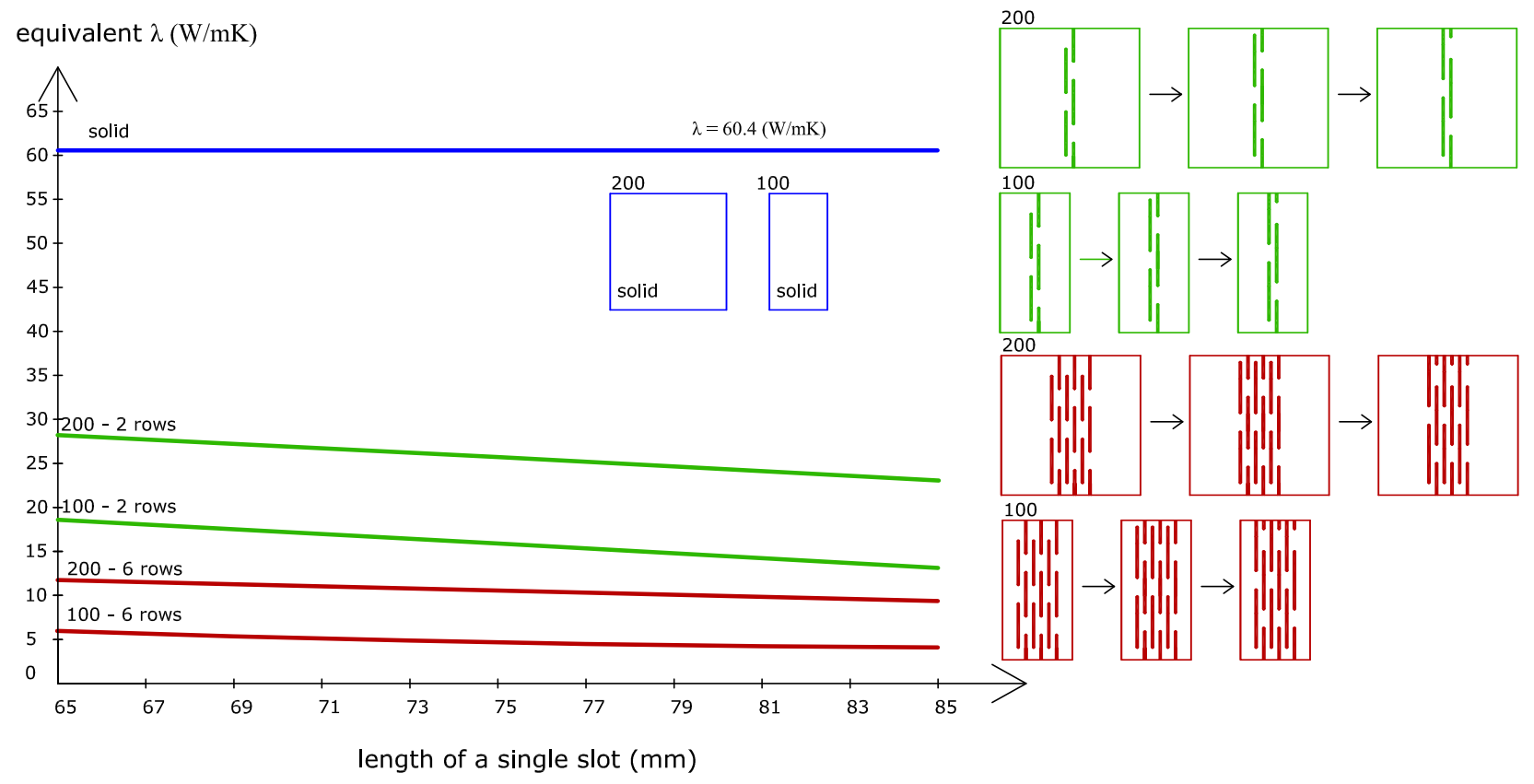

Fig. 5. The effect of changing the single slot length (6 and 2 rows of slots)

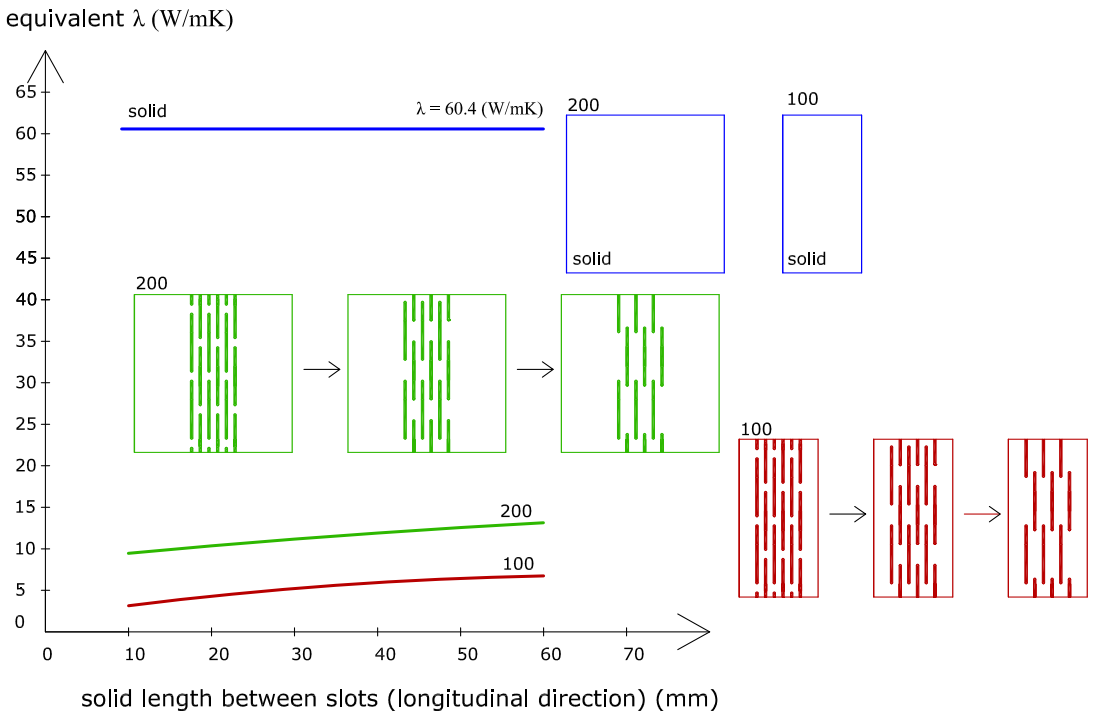

Fig. 6. The effect of solid length (longitudinal direction)

Based on these calculations it can be said that the increase in the thickness of the slots, the increase in the number of rows of slots decrease the equivalent thermal conductivity value. The increase of the solid length between the slots both in vertical and horizontal direction and the increase in web height increase the thermal conductivity value.

\subsection{The use of the equivalent thermal conductivity}

As a next step it was a question if the previously calculated equivalent thermal conductivity values can be used in the complex models of wall sections. Sections with the perforated web and the same wall sections containing solid webs with equiva- lent thermal conductivity values were compared to each other. 27 different types of slotted girders were used in the wall sections. The model used in the simulations can be seen in Fig. 9 The layers of the calculated section are: $12.5 \mathrm{~mm}$ gypsum board, $100,110,120,150,200,300 \mathrm{~mm}$ insulation with the steel girder, $12.5 \mathrm{~mm}$ gypsum board, $50 \mathrm{~mm}$ external insulation.

Calculations of comparing the wall section containing once slotted web then the solid web with the equivalent thermal conductivity values showed good agreement, a few results can be seen in Table 3 .

There were cases when the two calculations gave the same results. The highest difference was $0.5 \%$. So it can be said that in 
equivalent $\lambda(\mathrm{W} / \mathrm{mK})$

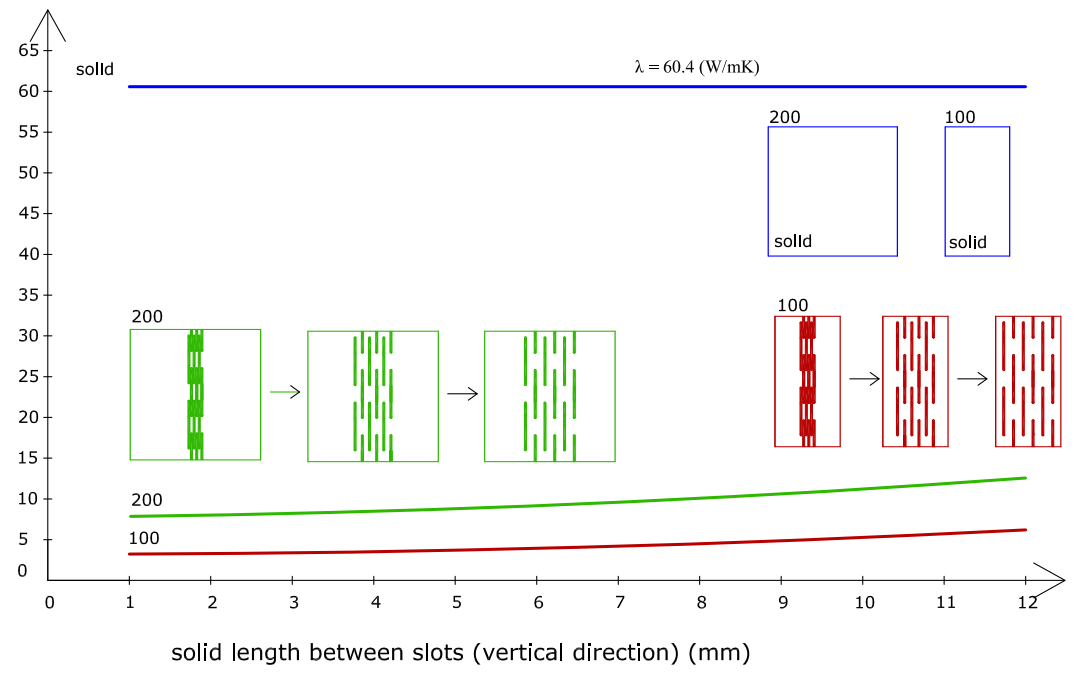

Fig. 7. The effect of solid length (vertical direction)

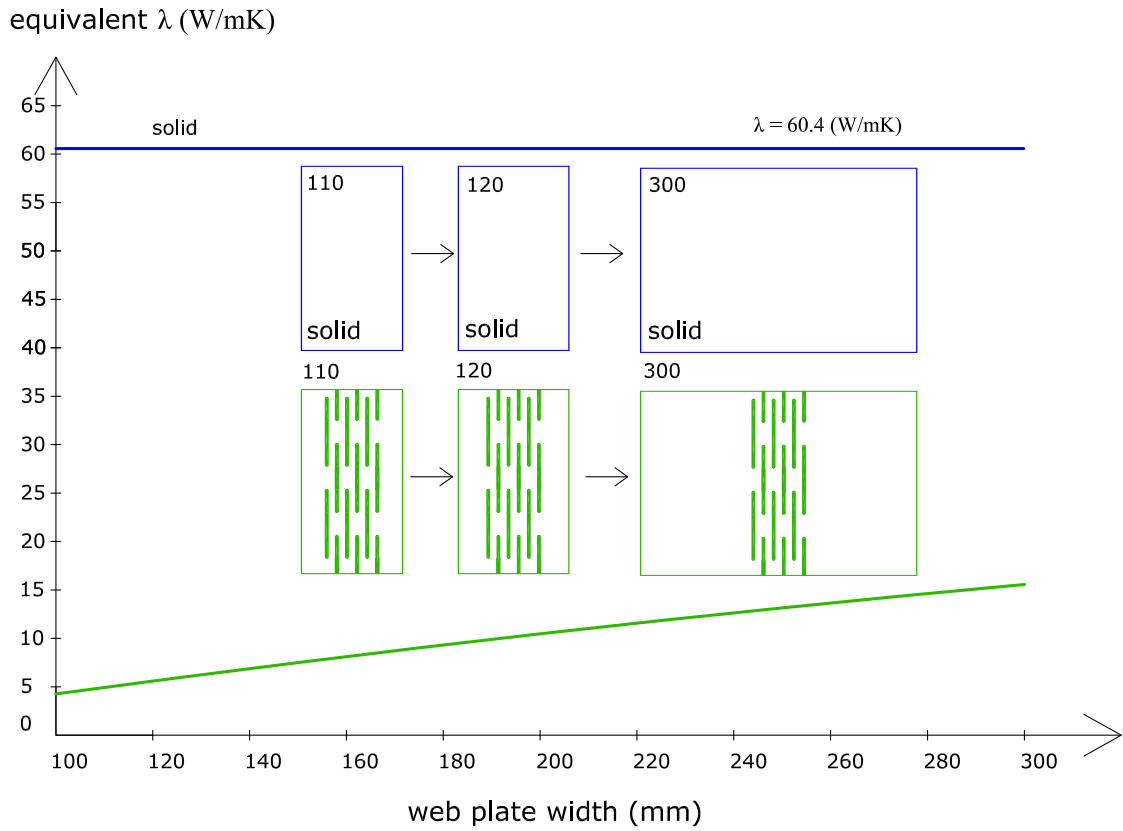

Fig. 8. The effect of web platewidth/thickness ratio

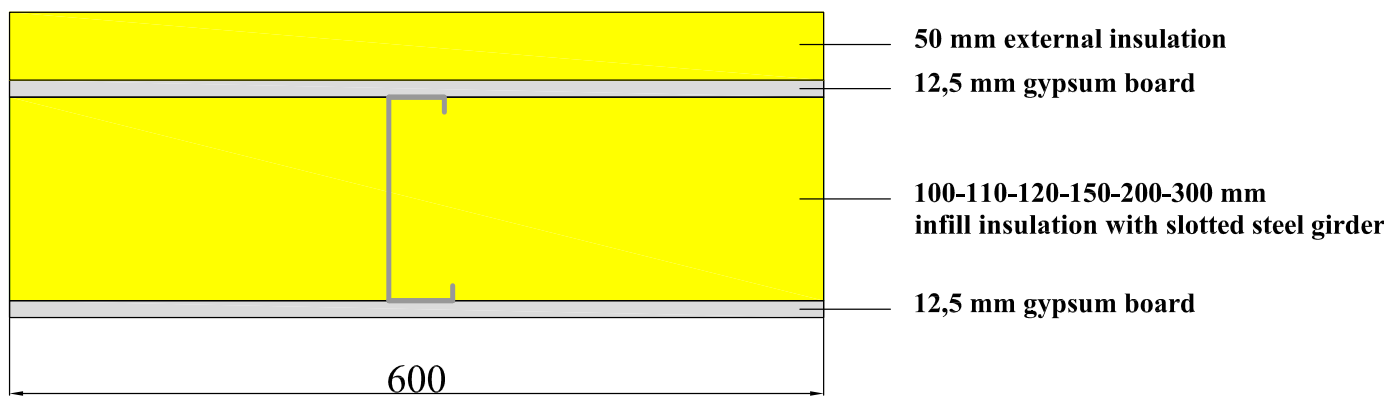

Fig. 9. Cross section of one of the calculated wall sections 
Tab. 3. Some comparison for using the equivalent thermal conductivity of the slotted web

\begin{tabular}{|c|c|c|c|c|}
\hline & $\begin{array}{c}\lambda_{\mathrm{eq}} \\
{[\mathrm{W} / \mathrm{mK}]}\end{array}$ & $\begin{array}{l}q_{\text {slotted }} \\
{\left[\mathrm{W} / \mathrm{m}^{2}\right]}\end{array}$ & $\begin{array}{c}q_{\mathrm{eq}} \\
{\left[\mathrm{W} / \mathrm{m}^{2}\right]}\end{array}$ & $\begin{array}{c}\text { difference between } \\
q_{\text {slotted }} \text { and } q_{\mathrm{eq}}\end{array}$ \\
\hline $\begin{array}{l}200 \mathrm{~mm} \text { web height, } \\
\text { perforation pattern geometry: } \\
n=6, l=25, p=3, d=75, s=9\end{array}$ & 11.00 & 0.1726 & 0.1726 & $0.00 \%$ \\
\hline $\begin{array}{l}150 \mathrm{~mm} \text { web height, } \\
\text { perforation pattern geometry: } \\
n=6, l=25, p=3, d=75, s=9\end{array}$ & 8.20 & 0.1996 & 0.1996 & $0.00 \%$ \\
\hline $\begin{array}{l}100 \mathrm{~mm} \text { web height, } \\
\text { perforation pattern geometry: } \\
n=2, l=25, p=3, d=85, s=8\end{array}$ & 9.77 & 0.2641 & 0.2628 & $0.50 \%$ \\
\hline
\end{tabular}

Tab. 4. The equivalent thermal conductivity values for the developed slotted webs

\begin{tabular}{lccccc}
\hline & $q\left[\mathrm{~W} / \mathrm{m}^{2}\right]$ & $\lambda_{e q}[\mathrm{~W} / \mathrm{mK}]$ & $\begin{array}{c}\text { ratio of } \lambda_{\mathrm{eq}} \\
\text { compared to } \\
\text { the basic geometry }\end{array}$ & $\begin{array}{c}\text { ratio of } \lambda_{\mathrm{eq}} \\
\text { compared to solid web } \\
\text { with } \lambda=60.4 \mathrm{~W} / \mathrm{mK}\end{array}$ \\
\hline 1. & Basic geometry & 5.38 & 5.22 & $100 \%$ & $8.6 \%$ \\
2. & Variation 1 & 5.28 & 4.40 & $84 \%$ & $7.3 \%$ \\
3. & Variation 2 & 5.10 & 3.38 & $65 \%$ & $5.6 \%$ \\
4. & Variation 3 & 4.82 & 2.44 & $47 \%$ & $4.1 \%$ \\
5. & Variation 4 & 5.06 & 3.21 & $62 \%$ & $5.3 \%$ \\
6. & Variation 5 & 5.07 & 3.28 & $63 \%$ & $5.4 \%$ \\
\hline
\end{tabular}

complex models the solid web with equivalent thermal conductivity values can be used instead of the slotted webs. This has many advantages such as simpler model generation in the finite element analysis and this simpler model can also speed up the numerical solution.

\subsection{Development of special slot geometries}

After changing the straight slot geometries, special slot geometries were developed by the author, also. The results were compared to the slotted steel girder used in Hungary, with the slot parameters: $d=75 \mathrm{~mm}, l=25 \mathrm{~mm}, p=3 \mathrm{~mm}, s=9 \mathrm{~mm}$. The thickness of the web was taken to $1 \mathrm{~mm}$ again. The longitudinal length of the slots was kept at the basic value $75 \mathrm{~mm}$. In the cases 2-4 the vertical amplitude of the wave patterns were increased. In the variations 5 and 6 the basic idea was to put slots perpendicular to the way of the heat flow to achieve a longer way for the heat flow to cross the web. The basic and the special, developed geometries can be seen in Fig. 10 .

The results of calculations can be seen in Table 4.

Compared to the basic geometry there is a major decrease in heat flow and the equivalent thermal conductivity value due to the special, developed slot geometries in the web. However, further researches are needed how does the slot geometry affect the stability behaviour of the steel element. After these researches and experiments an optimum perforation geometry can be offered which has favourable thermal conductivity and stability behaviour, also.

\section{Conclusions}

There is correlation between the geometry of the slots found in the web of the steel girders, and the amount of heat flow going through the web. The slots affect the thermal conductance of the façade in a high degree. I collected the different types of slotted steel girders used around the world and in Hungary, and analysed the thermal behaviour of the webs with different slot geometries. I suggested development directions and developed different slot geometries to achieve notable decrease in the equivalent thermal conductance of the web.

During the thermal analyses of facades and different thermal bridges, in many cases it is a problem, that multidimensional numerical model and a high number of finite elements are needed, so the calculation time and the expenses increase, also. To solve this problem it is recommended to use an equivalent thermal conductivity for the slotted webs in the complex numerical models. The simulations led to the same results in the case of using the slotted web or a solid web with the equivalent thermal conductivity, also. Based on computational simulations I proved, that it is possible to give an equivalent thermal conductivity for the slotted web and to use it in further, complex models. 


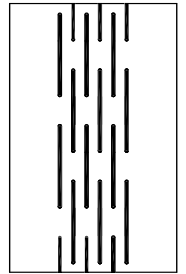

1.

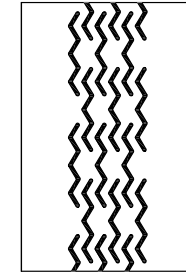

2.

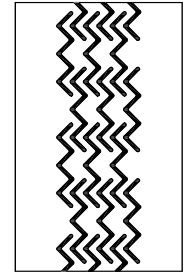

3.

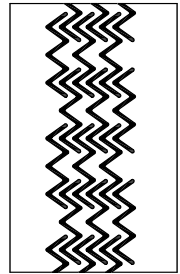

4.

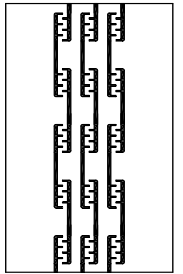

5.

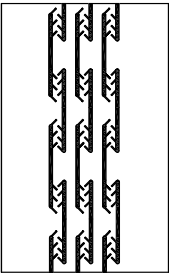

6.

Fig. 10. Special slot geometries compared to the basic geometry (from left to the right: 1. basic geometry, 2-6. special, developed geometries)

\section{References}

1 Sebestyén Gy, Lightweight building construction, Akadémiai Kiadó, Budapest, 1977.

2 Falprofil inspiration, Lindab Ltd., Budapest, Hungary, 2007. http://www.lindab.hu.

3 Höglund $\mathbf{T}$, Burstrand $\mathbf{H}$, Slotted steel studs to reduce thermal bridges in insulated walls, Thin-Walled Structures 32 (1998), 81-109.

4 Váradi J, Tóth E, Thermal Improvement of Lightweight Façades Containing Slotted Steel Girders, The Twelfth International Conference on Civil, Structural and Environmental Engineering Computing (Funchal, Portugal, 2009), 2009, pp. No. 107.

5 Csermely G, Lightweight buildings, TERC Kiadó, Budapest, 2005.

6 Sakumoto Y, Nomura H, Dohnomae H, Kanno R, Steel-Framed Houses, Environmentally Friendly Houses, 2000.

7 Joó AL, Ádány S, FEM-based approach for the stability design of thinwalled members by using cFSM base functions, Periodica Polytechnica in Civil Engineering 53 (2009), no. 2, 61-74.

8 Kosny J, Christian JE, Desjarlais AO, Improving Energy Performance of Steel stud Walls, Steel Framing Can Perform As Well As Wood, 2001. http://www.ornl.gov.

9 Amundarain A, Assessment of the Thermal Efficiency, Structure and Fire Resistance of Lightweight Building Systems for Optimised Design, Edinburgh, UK, 2007. $\mathrm{PhD}$ thesis.

10 Amundarain A, Torero JL, Usmani A, Al-Remal AM, Light Steel Framing: Improving the Integral Design. http://www.era.lib.ed.ac.uk/handle/ 1842/1409.

11 De Meo L, de Souza K, Vella J, Rice J, Investigation of the Thermal Performance of Steel and Wood Framed Homes Using Infrared Thermography, 1998. http://www.dofasco.ca/.

12 Sasaki JR, Thermal Performance of Exterior Steel-Stud Frame Walls., 1972. http://www.nrc-cnrc.gc.ca.

13 Blomberg T, HEAT3. A PC-Program for heat transfer in three dimensions, 2001. http://www.buildingphysics.com.

14 Salonvaara M, Nieminen J, Hygrothermal Performance of a New Light Gauge Steel-Framed Envelope System, Journal of Building Physics 22 (1998), no. 2, 169-182.

15 Salhab B., Wang YC, Equivalent thickness of cold-formed thin-walled channel sections with perforated webs under compression, Thin-Walled Structures 46 (2008), 823-838.

16 ANSYS Release 11.0 Documentation, Ansys Inc., 2007.

17 MSZ-04-140-2:1991 Power Engineering Dimensioning Calculuses of Buildings and Building Envelope Structures (in Hungarian), 1991.

18 MSZ EN ISO 6946 Building components and building elements. Thermal resistance and thermal transmittance. Calculation method, 2006.

19 MSZ EN ISO 10211 Thermal bridges in building construction. Heat flows and surface temperatures. Detailed calculations, 2007. 